\title{
3 Technologies for Teaching and Learning L2 Grammar
}

\section{TRUDE HEIFT AND NINA VYATKINA}

\section{Introduction}

Technologies take their respective places in the ongoing dispute over grammar teaching, which has been appropriately described as a "linguistic and political battlefield" (Metcalfe 1992) due to the ever-changing levels of acceptance of focusing on grammar in second language (L2) teaching approaches over the past decades. There have been periods during which grammatical accuracy was the prime goal, but there also have been times where the teaching of grammar was abolished altogether. These debates, however, not only focused on the central question of if and when grammar should be taught but also how it should be taught.

In a history with many apparent recommendations about grammar teaching, the debate has focused on two main approaches to grammar teaching: explicit and implicit. Explicit grammar teaching emphasizes rules as a form of metalinguistic knowledge and is equated with the deductive teaching of discrete points of grammar. An emphasis is placed on systematically teaching isolated linguistic forms by following a structural syllabus. In contrast, implicit approaches to grammar teaching are exemplar based and derive from the assumption that there are similarities between L2 learning and L1 acquisition and that comprehensible language input arising from natural interaction is central (see Krashen 1988). The overall focus of this inductive teaching approach is on meaning and/or communication rather than linguistic form. These two main approaches to grammar teaching are also reflected in the ways in which L2 grammar is taught and learned with technology. Yet, newer technologies are not limited to the traditional dichotomy of implicit and explicit teaching approaches. Instead, they emphasize both learner-computer and interpersonal interactions by promoting independent discovery and learner autonomy through the exploration of authentic language.

This chapter discusses four technology-based pedagogies for L2 grammar: tutorial CALL, intelligent CALL (ICALL), data-driven Learning (DDL), and computer-mediated communication (CMC). We first describe their respective goals and SLA frameworks and then provide examples of the tools developed for the L2 grammar classroom by situating each learning environment within its teaching approach to L2 grammar instruction. Finally, we present an overview of research studies that have been conducted within these learning environments by focusing on learner feedback in ICALL and CMC, and learner autonomy in DDL. 


\section{Four technology-based pedagogies for L2 grammar}

The origins of CALL in general as well as CALL-based L2 grammar teaching and learning in particular can be traced back to the 1960s. Influenced by the structural view of language dominant at the time, these CALL applications, commonly referred to as tutorial CALL, focused exclusively on explicit grammar teaching. Yet, due to technological advances and influenced by mainly the interactionist (Long 1996; Gass 1997) and sociocultural schools (Lantolf and Thorne 2006; Thorne 2003) of Second Language Acquisition (SLA), the teaching and learning of L2 grammar with technology shifted to emphasize the ways in which learners interact with the technology and their peers when they perform tasks and process language. Examples of such technologies are ICALL, DDL, and CMC which we discuss along with tutorial CALL in the following.

\section{Tutorial CALL}

In tutorial CALL, the computer takes on the role of a tutor (Levy 1997) by evaluating learner responses and presenting new material in one-to-one interactions. In early tutorial CALL applications, learners were provided with mechanical practice of selected and graded grammatical phenomena, such as the use of personal pronouns or verb tense, in the form of drills, similar to those commonly found in the face-to-face classroom during the prevalence of the Audio-Lingual Method up to the 1970s. The focus of tutorial CALL applications was on repetition and immediate feedback, which were provided while allowing students to work at their own pace and time. Later applications placed an increased focus on record keeping and the individualization of the learning experience by paying particular attention to branching, that is, the individualization of practice sequences based on prior student performance (Burston 1989).

Tutorial CALL follows a deductive teaching approach to grammar by presenting explicit explanations of grammatical concepts and by focusing language practice on graded and discrete grammatical points. The grammar learning activities mainly consist of short sentencebased practice and cover isolated grammatical forms which are presented as multiple choice, fill-in-the-blank, match or rank, and reassemble or translate small chunks of text items (Hubbard and Siskin 2004; Schulze and Heift 2013). These activities are nowadays integrated in authoring programs that allow teachers to generate grammar exercises without programming expertise (see e.g., Arneil and Holmes 1999).

One of the main differences among tutorial CALL programs lies in the ways in which learner responses are processed and evaluated. These underlying algorithms determine the distinct ways in which the CALL application responds to learner errors. The three most commonly used algorithms are string matching, pattern mark-up, and error anticipation.

Tutorial CALL applications which are based on string-matching algorithms and binary knowledge of answer processing compare the learner input with a pre-stored, correct answer (e.g., Williams, Davis, and Williams 1981). For instance, the grammar activity given in example (1) illustrates a typical tutorial CALL exercise which asks the learner to complete the sentence with the correct word form.
(1) Prompt:

Are you afraid of (to fly, fly, flying)? 
If the student answers with the infinitive "to fly," the system will identify that an error has occurred and respond with a generic error message (e.g., Wrong, try again!). However, even if the student chooses the correct answer "flying" but misspells it, the CALL program will provide the same error message and thus not make a distinction between different error types. Accordingly, and due to the underlying algorithm of processing learner input, simple string matching cannot channel learners toward the correct answer or focus their attention on the error. The algorithm is limited to a yes/no response.

Pattern mark-up is an example of a more sophisticated error processing algorithm also employed in tutorial CALL applications. Here, the computer makes a non-syntactic comparison of the student answer with the string stored as the correct answer, and also searches for variations on the correct response such as patterns consisting of inversions of characters, extra characters, missing words, extra words, and the like. Pattern mark-up was, for instance, implemented in the foreign language authoring package DASHER developed in the early 1980s (Pusack 1983). In a typical DASHER exercise, the program may instruct the student to change, for instance, the verb tense in a sentence by rewriting the entire sentence. The program then would scan the sentence left to right by performing a simple character-bycharacter match and informing the student of any character mismatch with a special symbol. While this answer-processing technique allows for less controlled and thus more challenging learning activities, a similar shortcoming as found with simple string-matching algorithms lies in its diagnostic capabilities in that it cannot explain an unanticipated error.

Finally, error anticipation, another popular answer-processing technique of tutorial CALL, is based on a collection of likely errors which commonly is established by means of a contrastive analysis between the L1 and L2 that the system targets in the learner response (see e.g., Liou, Wang, and Hung-Yeh 1992). Each error is associated with a pre-defined error message but the CALL program cannot provide informative feedback for errors which are not anticipated. For instance, if the student answers to fly for the activity in example (1) and the error has been anticipated, the system will be able to identify the error and inform the student that the infinitive is wrong because "afraid of" requires a gerund. In contrast, if the error has not been anticipated, the system response will result in a generic feedback message.

Despite relatively high levels of sophistication of the answer processing techniques in some tutorial CALL applications, the main challenges and limitations remain: the underlying algorithms are not scalable because the number of ill-formed responses that students might make to a prompt is infinite and thus cannot be anticipated. For this reason, the computer needs to be capable of a more sophisticated linguistic analysis of student input to detect errors and provide instructional guidance. Broadly speaking, this approach is taken in ICALL, which enriches the L2 grammar learning experience by providing contextual learner feedback and instructional guidance based on the complex linguistic processing of students' textual input.

\section{ICALL}

ICALL relies on natural language processing (NLP), student modeling, and expert systems. NLP techniques model "understanding" of human language by a computer by producing a formal linguistic representation of learner input with the goal to provide informative and error-specific corrective feedback, instructional guidance and scaffolding, and information about the learner's current interlanguage state. The record of this information over time, which is maintained in student profiles, provides the basis for the construction of a student model. Expert systems provide the knowledge base of the facts and rules about the language. They represent a rich source of linguistic knowledge that can guide and scaffold learning processes, enable learners to query this knowledge base during task completion, and serve as a comprehensive reference tool in learner-computer interactions. Most ICALL 
applications for L2 grammar teaching and learning can broadly be categorized into two main categories: Intelligent Language Tutoring Systems (ILTSs) and language tools.

The article by Weischedel, Voge, and James (1978) is commonly cited as the first publication that reports on an ILTS which the authors developed for L2 German. The main advantage of ILTSs over tutorial CALL applications lies in its contextual corrective feedback in response to learner output. ILTSs place a strong focus on learner-computer interactions (Schulze and Heift 2013). However, these ICALL applications illustrate a different type of interaction and noticing process in the face-to-face interactions and classroom learning, where interactionist SLA originated. ICALL creates opportunities for learner-computer interactions with computer reactions and responses to learner output, error detection, and error-specific feedback, and they draw the learners' attention to a gap between their interlanguage and the target language through salient modified language input. Accordingly, and based on sophisticated NLP technologies, an ILTS identifies and interprets errors as well as correct constructions in learner input and then generates pedagogically appropriate, informative learner feedback by instructing the learner as to the exact location and source of an error. Example (2) illustrates such error-specific, metalinguistic feedback with a sentence-building activity which requires the learner to form a German sentence by providing missing articles and inflections.

(2) Prompt: Kind/noch/klein/sein

child/still/young/to be

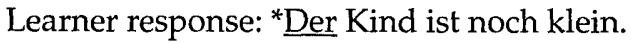

Correct answer: Das Kind ist noch klein.

The child is still young.

If the student incorrectly provides the article Der for the noun Kind, the ICALL system informs the learner that an error has occurred with the article of the neuter noun. In addition, an ILTS is capable of distinguishing among different types of errors. For instance, if the student misspells a word (e.g., "Kint" instead of "Kind"), the system also instructs the learner accordingly. Unlike tutorial CALL, ICALL is able to provide appropriate feedback to a large range of unanticipated errors that the student may make.

Examples of ILTSs that are used in regular L2 curricula are E-Tutor (Heift 2010) for L2 German, Robo-Sensei (Nagata 2009) for L2 Japanese, and Tagarela (Amaral and Meurers 2011) for L2 Portuguese. These three ICALL systems present materials to students in the form of an electronic textbook. As the students complete the exercises, the system provides feedback on spelling, morphological, syntactic, and semantic errors for L2 grammar practice. Due to the more sophisticated NLP analysis of ILTSs, their learning environments and activity types are also less restricted than those found in textbooks and especially than those found in tutorial CALL. An ILTS may also reflect an inductive approach to teaching and learning L2 grammar and emphasize peer collaboration and interaction during a goal-oriented CALL activity (see Thorne 2003). For instance, Dickinson et al. (2008) designed an ICALL system for teaching particle usage for first-year L2 Korean learners embedded in a CMC environment in which dyads engage in an information-gap activity. Learners are presented with a spot-the-differences task of two different cross-sections of a house and must identify similarities and differences in the actions and locations of family members shown in the two versions. The dyads construct Korean sentences by dragging words from a word bank and can obtain corrective feedback from the ICALL application on the grammaticality of their sentences before submitting them to their peer in a chat box. In contrast to explicit grammar teaching, however, the emphasis and goal of the activity is to provide an authentic, communicative task and the decision to check the grammaticality of their message with the ICALL application is left up to the learner. 
In addition to ILTSs, a variety of ICALL language tools have also been developed to assist learners with their L2 grammar. In these environments, the computer takes on the role of a tool (Levy 1997) by empowering the learner to use or understand language and by enhancing L2 grammar awareness with strategies that highlight the salience of language categories and forms (Sharwood Smith 1993). Schmidt's (1990) Noticing Hypothesis underpins some of this ICALL work by recognizing the role of consciousness in L2 learning and drawing the learners' attention to salient grammatical forms. For instance, Meurers et al. (2010) designed WERTi, an NLP architecture which provides visually enhanced versions of web pages. Language input enhancement is achieved by highlighting and annotating certain grammatical forms (e.g., determiners, prepositions) that generally pose difficulties for ESL learners. These grammatical forms appear in texts that learners freely select from the internet. Similarly, The Microsoft Research ESL Assistant developed by Gamon et al. (2009) is a web-based proofreading tool designed primarily for L1 speakers of East-Asian languages studying ESL. The system targets a variety of syntactic, morphological, and lexical selection errors. With the goal to stimulate language awareness, The ESL Assistant displays correction suggestions by allowing users to explore and compare their language production with real-world examples it found on the internet.

In addition to these more comprehensive ICALL tools, students may also have contingent access to online dictionaries (e.g., Hamel 2010), grammar, and spell checkers (e.g., Burston 2001; Cowan et al. 2014), and morphological analyzers (e.g., ten Hacken and Tschichold 2001; Wood 2011) which generate context-sensitive inflectional paradigms (e.g., Heift 2010) that assist learners with their language learning activities.

\section{Corpora and Data-driven Learning}

Corpora, or large electronic collections of texts, have been applied for the purposes of language learning and teaching since their emergence in the late 1960s (Chambers 2005). Such applications can be of both indirect and direct nature. In indirect applications, corpus-based research studies have informed the development of new teaching materials: reference grammars and textbooks that accurately reflect actual language usage and that use attested and not invented examples. Over 25 years ago, however, priorities in the use of corpus research for language teaching expanded to include direct applications, although the origins of such applications are in the 1980s (Higgins and Johns 1984; Johns 1986). Johns (1991) singled out direct corpus-based applications as a distinct language teaching and research direction and called it DDL, adopting a term from computer science. Since then, the pedagogical variations that can be developed based on DDL have been expanding continuously (see Boulton and Pérez-Paredes 2014; Römer 2011 for overviews).

Theoretically, DDL is consistent with Usage-Based Grammar theory (e.g., Robinson and Ellis 2008) as we know it today, namely with its four principles. According to the first principle, languages are learned from exposure to specific linguistic exemplars in the environment that leads learners to gradually make generalizations and create linguistic rules. The second principle is that grammar and the lexicon are inextricably intertwined. Accordingly, in most DDL interventions, the teaching of grammar is integrated with the teaching of the lexicon and the main object of study is referred to as "lexico-grammar" (Chambers 2005; Conrad 2000). The third principle is what Conrad (2000) described as "a new view of grammar" (558) that takes into account choices that learners make among possible grammatical alternatives rather than purely formal accuracy. The fourth principle is the primacy of rich and salient target language input for language learning. Corpora are potential sources of rich language input as they allow teachers and learners to obtain large numbers of 
examples of target constructions (if the selected corpus is representative of these constructions). Furthermore, using concordancer tools for retrieving corpus search results makes the language input salient. This visual salience, or input enhancement, is realized through concordance lines, or stacked text excerpts with the search words highlighted and centered. For example, the search string depend* entered in the Michigan Corpus of Academic Spoken English (MICASE) (Simpson et al. 2002) concordancer interface yields 598 matches, an excerpt from which is presented in Figure 3.1. The visual highlighting of the words containing the stem depend facilitate analysis of usage patterns. Among other things, the learners may infer from this analysis that depend may function as the stem of verbs, participles, nouns, and adjectives; that the forms of the verb to depend are most frequently followed by the preposition on and sometimes upon, and that the noun dependency can be followed by the preposition between. Furthermore, by clicking on marginal links provided in each concordance line (not shown in Figure 3.1), the learners can see the whole transcript containing the line as well as contextual information (speaker ethnographic information, academic event type, etc.).

Owing to these characteristics, corpora lend themselves to an inductive approach to language teaching and learning, in which learners more or less independently engage in "pattern-hunting" and "pattern-defining" (Kennedy and Miceli 2010, 31) with the teacher assisting them as a facilitator. Furthermore, DDL has also been associated with learner autonomy: "the learner's psychological relation to the process and content of learning-a capacity for detachment, critical reflection, decision-making, and independent action" (Little 1991, 45). This emphasis on independent discovery, serendipitous learning, and learner autonomy has been reflected in metaphors like "researcher" and "observer" that have been used to describe a learner engaged in DDL. The number of resources providing guides and models for specific DDL activities for teachers and learners (e.g., Reppen 2010) has been recently growing, although still is insufficient (Römer 2011).

Although corpora have sometimes been referred to as research and teaching "tools," they are rather repositories of texts, which need to be distinguished from software tools that are required for their exploration (Anthony 2013). The corpora most frequently used for DDL purposes are large English native speaker corpora such as the British National Corpus (BNC) and the Corpus of Contemporary American English (COCA). However, increasingly more DDL studies have been reporting on the utilization of specialized corpora (Bloch 2009), learner language corpora (Cotos, 2014; Granger 2003), and corpora in languages other than English (Kennedy and Miceli 2010; Vyatkina 2013, 2016a, 2016b).

As far as corpus search and analysis tools are concerned, large online corpora are typically equipped with a number of built-in software tools that can be used either with free access or with the publisher's permission; in contrast, for utilizing locally designed corpora, researchers and teachers have to rely on external software or design their own tools (Anthony 2013). Tools beyond concordancers (see Figure 3.1) include annotation programs that allow for tagging raw corpus data for abstract grammatical categories and are thus especially valuable for DDL of L2 grammar (e.g., lemmatizers, part-of-speech (POS) taggers, syntactic parsers) and statistical analysis and visualization programs (e.g., key word lists, ranked word frequency lists, word association strength measures, distribution plots). For example, the search string prep.ALL in the "Chart" interface of COCA (Davies 2008), yields a chart showing how all prepositions are distributed among different genres/registers (Figure 3.2). It is revealing to see that prepositions are used with the highest frequency in academic texts and with the lowest frequency in spoken texts. This finding confirms that academic texts are characterized by a "nominal" style (with a high frequency of prepositional phrases) as opposed to spoken texts (see Biber 1988). An encouraging development is that several recent DDL publications have presented new online corpus-based grammar resources (concordancers and other tools), some of which are available to other teachers and researchers (e.g., Bloch 2009; Hegelheimer 2006). 
better to take a bunch of samples from the lab rather than to do a pump test. so it endent and this one is also dependent this one is also

LAUGH um... and, what's assumed is that my utility in those years cate with like sign language.

, there's no, hard and fast yes or no fact about you who you are, it's, who you are whether ninety-one or ninety-two or ninety-three percent ends up being an A just e top story on the online edition, when they start the day but of course it'll change because, you can't just tell it

re. so, if this is independent but this is dependent, then this is still_ then there is that $i$ don't need and $i$ think it detracts from leaming sometimes, so $i$ think it really Ind we have to form a supply chain. um, so let me explain the portions of the task $s$ an experiment that $i$ think is pretty cool to introduce you to a concept of dosage depends dependent depends depends depends depending depending depends

dependency depends

dependence dependent upon what you're trying to predict, and how you're gonna use the information. but no the right? oh. so i mean th- th-

on the retirement benefits that $i$ get in each of those years... okay so notice that there's on the aphasia. um, if in my uncle's case yes he actually was educated in a school for t on how well integrated your thoughts and feelings are over time. the more psychologica on where students fall and what your G-S-Is tell me, about um, about how you guys per on what other news breaks. okay? so take a, just very quickly read through some of the on, the env-cell environment

between the two so you have to find to see if every path between two nodes is indepenı on whether you're, already a very motivated individual, or whether you need, like extern network. now these circles throughout the network represent the tasks or the resources

Figure 3.1 


\section{CORPUS OF CONTEMPORARY AMERICAN ENGLISH}

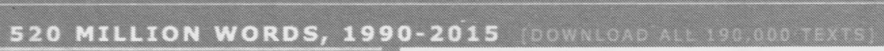
DISPLAY 2 CLICK ON BARS FOR CONTEXT

OUST OCHART OKWIC CCOMPARE SEARCH STRING WORD(S)

COLLOCATES

POS LIST

RANDOM SEARCH RESET

SECTIONS \& SHOW

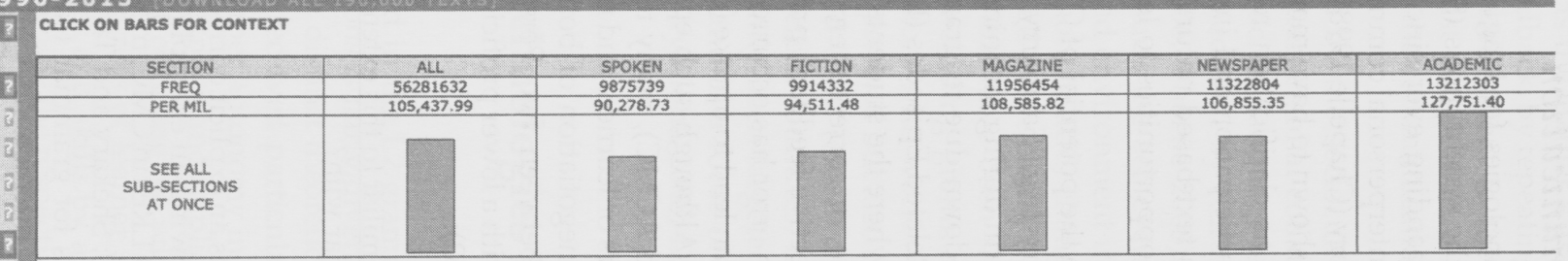

Figure 3.2 


\section{Computer-mediated communication}

The first attempts to use CMC technologies for language teaching purposes, primarily the asynchronous (ACMC) email and the synchronous (SCMC) chat, were made in the 1990s, and the field has been rapidly expanding ever since. Such pedagogical applications are grounded in theories that consider interpersonal communication a crucial driving force in L2 development: the interactionist theory (Chapelle 1998) and the sociocultural theory (Thorne 2003). Furthermore, $\mathrm{CMC}$ has been shown to have many features similar to face-to-face language classroom interactions such as clarification requests and feedback, but also some added benefits such as increased participation and improved learner attitudes (Chun 1994; Kern 1995). Additionally, due to its text-based nature, CMC provides more planning time and more monitoring and revision opportunities to learners as compared with face-to-face communication.

The first studies that reported on the potential of CMC for teaching of L2 grammar were informed by the interactionist theory (e.g., Salaberry 2000). They showed that L2 learners incidentally focused on language form during meaning-oriented CMC exchanges with their peers when communication broke down due to grammatical errors. Such incidents were manifested in so-called Language-Related Episodes (LREs), defined in face-to-face communication as "any part of a dialogue where the students talk about the language they are producing, question their language use, or correct themselves or others" (Swain and Lapkin 1998, 326). LREs could include corrective feedback provided by peers which can be explicit (if it includes an overt signal that an error has occurred) or implicit (without such a signal). Both explicit and implicit feedback can lead to uptake (error correction) by learners if noticed, understood, and accepted by them. Although such episodes occur virtually in any peer-topeer L2 exchanges (both SCMC and ACMC), many teachers-researchers choose to pair up lower and higher proficiency learners or learners and native speakers as such configurations have been shown to trigger more negotiation of both meaning and form. The following excerpt from an SCMC exchange between two Persian learners of English-one with a higher $\mathrm{L} 2$ proficiency $(\mathrm{H})$ and one with a lower proficiency $(\mathrm{L})$ - exemplifies such an interaction (Shekary and Tahririan 2006, 562):

Far (L): I mean I can at least be familiar to this extensive major.

Fatem $(\mathrm{H})$ : isn't it better to say familiar with?

Far (L): all right, familiar with

In this excerpt, Fatem $(\mathrm{H})$ suggests an explicit correction of Far's error, and Far $(\mathrm{L})$ accepts this correction in the next move, showing an example of uptake.

Despite this frequent occurrence of LREs in CMC, most of them revolve around lexical rather than grammatical targets (Blake 2000; Shekary and Tahririan 2006). This fact prompted many educators wishing to use these tasks for grammar teaching to add some planned focus on grammar to primarily meaning-based interactional CMC tasks. In peer-to-peer exchanges with such added focus, learners are instructed to give each other feedback on grammar in general or on specific grammatical forms. Furthermore, instructors can themselves participate in CMC interventions, acting as expert communication partners and providing corrective feedback to learners, as in the following SCMC example from Samburskiy and Quah $(2014,166)$ :

Learner: As i [sic] understand your stay in China has affected you. I have never tasted Chines [sic] cuisine but I know that it [sic] very specific and exotic. They cook fried worms, beetles, rats ... Is it true? Do [sic] you tasted this?

Teacher: Well, they do eat some exotic things in China. Have I tasted this? No, but I knew people who ate grubs, dragonflies, and things like that. 
In this example, the teacher corrects the learner's grammatical error (verb tense) using a recast, a type of implicit corrective feedback, by repeating the learner's utterance with targetlike grammar. To make the recast more salient to the learner, the teacher highlights the corrected form. From the interactionist perspective, a recast is less intrusive than explicit correction because it does not disrupt the communication flow while still drawing the learner's attention to form.

Pedagogical approaches informed by the sociocultural theory (SCT) framework have also capitalized on the benefits of interpersonal collaboration for language learning, yet from a different angle. In these approaches, language learning is conceived of as a sociallysituated and goal-directed activity mediated by culturally embedded tools such as technology (see Lantolf and Thorne 2006; Thorne 2003). One such social tool that "leads learners to work collaboratively towards the achievement of a common goal" (Elola and Oskoz 2011, 180) is wikis, a web-based environment in which several authors jointly construct a text. The tool allows all authors to add, change, and delete text as well as documents all previous drafts and tracks all made changes (see Elola and Oskoz 2011, 205-206 for a list of available wiki tools). Wikis have been shown to promote attention to both global and local language aspects (including grammar) and to encourage revisions and error correction. Furthermore, educators who work within the SCT paradigm have been especially interested not only in interpersonal but also intercultural (also called telecollaborative) exchanges and have organized CMC (email, chat, audio, and video conferencing) between language learners from different countries. L2 grammar in SCT-informed pedagogical interventions has predominantly been targeted not as an end goal but as a means for conveying specific social actions and as a focus of peer-to-peer mediation in the zone of proximal development (Belz and Vyatkina 2008; Darhower 2014; Oskoz 2009; Thorne 2003; Zeng and Takatsuka 2009).

\section{Research on the use of technologies for L2 grammar teaching and learning}

The research that has been conducted in the L2 grammar teaching and learning environments described in the previous sections is fairly diverse not only due to the different technologies involved but also due to the distinct theoretical and pedagogical approaches that underlie them. Two topics that have received particular attention, however, are corrective feedback in ICALL and CMC, and learner autonomy in DDL. Studies of corrective feedback in ICALL and CMC investigate both explicit and implicit grammar teaching approaches by exploring ways in which learners not only engage with the computer but also with their peers. DDL research examines the degrees of learner autonomy that are conducive to the learning of different linguistic features and skills by also considering distinct levels of L2 proficiency. The following sections examine the respective research carried out with a variety of learners in distinct learning conditions.

\section{Feedback for L2 grammar}

The provision of feedback on grammar is a central topic in L2 grammar teaching and learning, and accordingly, an area of research that has been pursued in both ICALL and CMC. Research on these two distinct, yet complementary environments focuses on learnercomputer and interpersonal interactions, respectively, by exploiting the strengths of different technology-mediated pedagogical approaches in providing explicit and implicit feedback for both form and meaning-based learning activities. 


\section{Feedback in ICALL}

In view of the powerful capacity of ICALL systems for generating error-specific feedback to learners, researchers examine the effectiveness of different types of corrective feedback on learners' L2 grammar performance to determine its impact on learning outcomes and/or learner-computer interactions. One of the early ICALL studies, for instance, investigated different feedback types for learning Japanese particles and found that error-specific metalinguistic feedback (see (2)) that explained the functions and semantic relations of nominal relations in a sentence was more effective than generic, traditional feedback (e.g., wrong, try again!) (Nagata 1993). A number of studies followed (e.g., Bowles 2005; Heift 2004; Heift and Rimrott 2008; Lado et al. 2014; Murphy 2007; Nagata 1996; Petersen 2010; Pujolà 2002; Rosa and Leow 2004) that generally supported the benefits of error-specific feedback in a CALL environment. However, a few studies also showed little or no advantage of metalinguistic feedback. For instance, Moreno (2007) investigated the effects of metalinguistic feedback compared to feedback that only signaled whether the student input was right or wrong. While both types led to an increase in scores on the immediate posttest, feedback without metalinguistic information was superior on the delayed posttest (see also Sanz and MorganShort 2004). Similarly, Kregar (2011) examined the effects of text enhancement and metalinguistic feedback on the acquisition of L2 Spanish verbal aspect and found that metalinguistic feedback was less effective than text enhancement.

In addition to these studies which investigated a reactive focus on form, that is, feedback that the ICALL system provides in response to learner input, a few studies have also examined preemptive focus on form which provides learners with relevant metalinguistic information before difficulties arise. The goal here is to reduce potential frustration by marking critical features in the language task to assist learners in task completion (Ellis, Basturkmen, and Loewen 2001). According to Ellis (1993), preemptive focus on form also assists in providing learners with explicit knowledge which helps improve performance through monitoring and facilitates acquisition through noticing. Heift (2013), for instance, investigated the impact of preemptive focus on form which consisted of exercise-specific grammar and vocabulary hints that the CALL system provided when students started an exercise. She showed that for different proficiency levels (beginner and early intermediate) of adult learners of German, preemptive focus on form was significantly more effective than not providing any assistance before students attempted to complete a task. Furthermore, according to retrospective interviews with some of the study participants, preemptive focus on form helped them avoid some errors thus also leading to a more positive learning experience.

While the research above focused on learning outcomes by studying the effectiveness of different feedback types, some studies have also considered learner strategies with respect to corrective feedback in CALL. For instance, Brandl (1995), studying L2 learners of German, found that lower-achieving learners, as determined by an initial placement test of reading comprehension, had a more limited set of strategies for processing feedback than learners of higher-achievement levels. Similarly, a study by Vinther (2005) investigated the difference in learner strategies employed by low- and high-achieving Danish university students of English as a foreign language. Her study confirmed Brandl's (1995) results by showing that high-performing students were more likely to make use of cognitive strategies throughout program use while lower-performing students employed only a few cognitive strategies, favoring affective strategies more, at least at the beginning of program use.

Some studies also examined learner error correction behavior in response to distinct feedback types thus focusing on the learning process as opposed to learning outcomes. The range of possible reactions and/or responses to corrective feedback is generally referred to as learner uptake. Research from face-to-face instruction (e.g., Lyster 2007) proposes that 
successful learner uptake is a good predictor of learning. Even in instances where no learning takes place at a particular moment, the research suggests that learners notice the feedback and process it, thereby increasing the likelihood of learning. As a result, researchers tend to view learner uptake as facilitative of L2 acquisition and examine its role when teaching L2 grammar with technology. For instance, Heift's (2002) study revealed that, when students were provided with error-specific feedback, the majority of them $(85 \%)$ sought to correct errors on their own for most of the time instead of looking up a correct answer made available to them in her ICALL system (see also Hegelheimer and Chapelle 2000).

Overall, this line of research has shown that students generally benefit from explicit, metalinguistic feedback because they subsequently perform better on particular target language structures and/or because students' grammatical awareness is subsequently raised. Nevertheless, there are conflating factors such as feedback amount and timing, or more generally, the long-term impact of CALL feedback on L2 learning that make the research results less conclusive than one might hope and require further investigation.

\section{Feedback in computer-mediated communication}

In CMC tasks for grammar learning, the feedback on learners' errors comes not from the computer but from other interlocutors and is manifested in LREs. To investigate the effectiveness of this feedback for L2 grammar learning from the interactionist perspective, researchers study (1) what specific CMC formats and pedagogical tasks are more conducive to grammar-focused LREs; (2) whether grammar-focused LREs lead to L2 grammar gains and whether these gains are higher in CMC than in face-to-face learning environments; and (3) what CMC feedback types lead to higher L2 grammar gains.

In the first research strand, most studies converge in their finding that vocabulary triggers more LREs than grammar in CMC interactions (e.g., Blake 2000). However, this finding holds true primarily for unmoderated interactions between peers. In contrast, both teachers and those learners who are instructed to provide corrective feedback in CMC, tend to focus on grammar either on a par with vocabulary (Bower and Kawaguchi 2011; Sotillo 2005) or even more (Smith 2009; Ware and O'Dowd 2008). Furthermore, ACMC has been found to trigger more LREs, including grammar LREs, than SCMC and within ACMC, wikis appear to be superior to forums for both peer and self-corrections (Bower and Kawaguchi 2011; Elola and Oskoz 2010). As far as specific feedback types are concerned, novice and native speakers have been found to provide more implicit and indirect feedback, whereas experts, especially non-native speakers, more explicit and direct feedback (Bower and Kawaguchi 2011; Oskoz 2009; Sotillo 2005).

The second strand has explored the CMC effectiveness for L2 grammar learning by measuring learning outcomes. Several studies have found higher accuracy gains following SCMC rather than face-to-face instructor-provided feedback focused on specific grammatical forms, such as Spanish tense and aspect morphology (Salaberry 2000) and Turkish noun morphology (Yilmaz 2012). In the context of peer-to-peer CMC, Stockwell and Harrington (2003) showed overall syntactic improvement in L2 Japanese learners' writing after a fiveweek-long ACMC exchange with native speakers. Hirotani (2009) also investigated L2 Japanese learners' development and showed that the SCMC group outperformed the ACMC group in accuracy but underperformed in syntactic complexity. Other studies focused on immediate learner uptake following LREs in CMC and found it to be fairly successful at up to $70 \%$ (Bower and Kawaguchi 2011; Zeng and Takatsuka 2009). Notably, Smith (2012) extended this line of research by correlating learner production outcomes with noticing. The learners noticed approximately the same amount of intensive SCMC recasts for all linguistic categories (measured with an eye-tracking methodology), whereas lexical and syntactic recasts triggered more learner recall than did morphological recasts. Smith also showed that 
the amount of both online and offline noticing predicted improvement on posttest performance, which lends support to using CMC feedback for L2 teaching purposes.

In the third strand, researchers have compared the effects of different feedback types on grammar learning. Vinagre and Muñoz (2011) showed that metalinguistic feedback led to more successful uptake than direct corrections in new pieces of writing in intercultural peerto-peer ACMC exchanges. Results from studies that measured learner gains after receiving explicit and implicit expert SCMC feedback on specific grammar features vary across target features and learner populations. Yilmaz (2012) found that explicit feedback provided on noun morphology to learners with no knowledge of Turkish was more effective than implicit feedback (recasts). Similarly, Sauro (2009) found that only metalinguistic feedback but not recasts on English articles provided to advanced learners was significantly better than no feedback. On the contrary, Loewen and Erlam (2006) found no feedback effect and no difference between the feedback types for beginning L2 English learners' acquisition of past tense morphology. The discrepancies in findings can be explained by variation in the target features and research designs. Furthermore, socioculturally-informed studies have provided insight into the versatility of peer-to-peer scaffolding patterns as well as learner preferences regarding self-corrections and peer-corrections (Darhower 2014; Oskoz 2009; Ware and O'Dowd 2008; Zeng and Takatsuka 2009).

To summarize, CMC has been shown to be effective for L2 grammar learning in both expert-to-learner and peer-to-peer intercultural and intracultural exchanges due to the frequent occurrence of LREs, enhanced visibility of feedback, and extended time for feedback processing. In a rare meta-analysis study, Ziegler (2013) confirmed that SCMC had a small yet significant advantage over face-to-face interaction for L2 grammar gains. Although results regarding feedback types that work best in CMC exchanges are less conclusive, all researchers concur that for CMC feedback to be beneficial, it needs to be based on wellstructured tasks that are tailored to specific CMC formats, learner populations, and grammar features.

\section{Learner autonomy in DDL of L2 grammar}

Language learning with technology has long been associated with higher degrees of autonomy, which is considered beneficial for learners as it prepares them for life-long learning beyond the classroom (Warschauer 2002). Given that DDL, by definition, is "a language-learning environment focusing on learner autonomy and discovery learning" (Chambers 2005, 120), it is not surprising that most DDL research has addressed the construct of learner autonomy. Specifically, this research has explored what degrees of autonomy are conducive to the learning of what specific linguistic features and skills, at what levels of L2 proficiency, and under what conditions. Furthermore, whereas the benefits of corpora for lexical learning were recognized long ago, some scholars have recently argued that DDL can be equally conducive to grammar learning and even especially facilitative at lowerproficiency levels as it requires less metalinguistic knowledge than explicit grammar teaching (Boulton 2010; Estling Vannestål and Lindquist 2007). In regard to pedagogical designs, DDL studies can be subdivided into hands-on (more autonomous, direct, computer-based) and hands-off (less autonomous, indirect, paper-based) applications (see Boulton 2010 for an overview).

Much L2 grammar research on hands-on DDL has been exploratory and demonstrated by way of case studies the potential of learner use of corpora for grammar consultation (Chambers 2005; Estling Vannestål and Lindquist 2007; Kennedy and Miceli 2010). The number of quantitative studies has been small but recently growing. Such studies have explored whether learning outcomes improve after DDL activities or have compared the outcomes of DDL as a mostly inductive teaching method with those of more traditional 
deductive teaching methods. All L2 grammar studies had university students as participants and most of them focused on teaching English. One of the first studies was Gaskell and Cobb (2004) who found that concordance searches helped intermediate English learners significantly reduce the number of writing errors in some categories (e.g., word order, pronoun use) but not others. This result is in line with a recent study by Tono, Satake, and Miura (2014), who found that guided corpus consultations helped high-proficiency, but not lowproficiency, learners to successfully self-correct omission and addition but not misformation errors in their revised essays. In contrast to the findings from hands-on DDL studies, research on hands-off DDL with printed concordance lines reported positive learning outcomes for both high- and low-proficiency learners. Moreover, whereas Tian's (2005) higher- and lowerproficiency groups equally improved after hands-off DDL instruction, Vyatkina (2016a) found that it was especially beneficial to lower-proficiency L2 German learners and was more effective for them than traditional deductive instruction. In contrast, most studies have failed to detect a significant advantage over traditional deductive methods for teaching L2 grammar to intermediate learners (Boulton 2010; Tian 2005; Vyatkina 2016a). Finally, studies that compared hands-on and hands-off DDL found them equally effective for teaching selected grammatical targets to intermediate learners of English (Boulton 2012) and German (Vyatkina, 2016b).

Finally, a number of recent studies have pinpointed specific principles of DDL that facilitate L2 grammar learning. Frankenberg-García (2014) confirmed that richness of language input (multiple concordance lines) is a crucial factor for the effectiveness of paper-based DDL; Cotos (2014) showed that DDL tasks based on comparison of native and learner corpora (consisting of texts similar to the native texts the learners used as models) are superior to DDL work on native corpora only; whereas Smart (2014) demonstrated that guided inductive instruction is better than three other conditions: non-guided induction, deductive instruction with corpus examples, and non-DDL deductive instruction.

To summarize, DDL has been shown to be effective (leading to significant learning gains) and efficient (more effective than deductive teaching methods), including for L2 grammar learning, as demonstrated by a substantial effect size in Cobb and Boulton's (2015) metaanalysis of available quantitative studies. However, the research has also convincingly demonstrated that for reaching positive outcomes, the principle of learner autonomy needs to be applied judiciously progressing from less to more autonomous tasks depending on the learner population and instructional context. Furthermore, any L2 grammar DDL needs to be guided by a teacher or tutorial program. Additionally, research has demonstrated advantages of problem-solving DDL tasks and the potential of using learner and parallel corpora for DDL grammar instruction. Last but not least, most researchers who have explored learner DDL perceptions, found those to be generally favorable, which provides yet another argument in support of this CALL method for teaching and learning L2 grammar.

\section{Conclusion}

This chapter outlined the variety of technologies teachers and researchers have explored for the teaching and learning of L2 grammar each of which reflects and promotes distinct affordances including language input, interaction, feedback, access to extensive language data, and opportunities for collaboration in different learning environments. Unlike traditional L2 grammar learning and teaching, newer technologies are not limited to the traditional dichotomy of implicit and explicit teaching approaches. They also place a strong focus on both learner-computer and person-to-person interactions by allowing learners to explore authentic language and promoting independent discovery and learner autonomy. Clearly, these technological changes have also had a direct impact on how L2 grammar learning and 
teaching is viewed by many language teachers. At the same time, and as supported by the studies cited above, language instructors are central to the successful realization of these new opportunities and affordances of L2 grammar learning and teaching independent of the particular technologies used. The involvement of instructors is crucial as they can trigger, stimulate, monitor, and guide online as well as offline activities conducive to L2 grammar teaching and learning. As a result of the pervasive use of technology, the way we teach grammar in the L2 classroom has been changing and therefore teachers need to be able to use technology-based approaches and materials with the goal to assist their learners.

\section{REFERENCES}

Amaral, Luiz, and Detmar Meurers. 2011. "On Using Intelligent Computer-Assisted Language Learning in Real-Life Foreign Language Teaching and Learning." ReCALL, 23, no. 1: 4-24.

Anthony, Laurence. 2013. "A Critical Look at Software Tools in Corpus Linguistics." Linguistic Research, 30, no. 2: 141-161.

Arneil, Steward, and Martin Holmes. 1999.

"Juggling Hot Potatoes: Decisions and Compromises in Creating Authoring Tools for the Web." ReCALL, 11, no. 2: 12-19.

Belz, Julie A., and Nina Vyatkina. 2008. "The

Pedagogical Mediation of a Developmental Learner Corpus for Classroom-Based Language Instruction," Language Learning $\mathcal{E}$ Technology, 12, no. 3: 33-52.

Biber, Doug. 1988. Variation Across Speech and Writing. Cambridge: Cambridge University Press.

Blake, Robert. 2000. "Computer Mediated Communication: A Window on L2 Spanish Interlanguage." Language Learning $\mathcal{E}$ Technology, 4, no. 1: 120-136.

Bloch, Joel. 2009. "The Design of an Online Concordancing Program for Teaching about Reporting Verbs." Language Learning $\mathcal{E}$ Technology, 13, no. 1: 59-78.

Boulton, Alex. 2010. "Data-Driven Learning:

Taking the Computer Out of the Equation." Language Learning, 60, no. 3: 534-572.

Boulton, Alex. 2012. "Hands-on/hands-off:

Alternative Approaches to Data-driven Learning." In Input, Process and Product: Developments in Teaching and Language Corpora, edited by James Thomas and Alex Boulton, 152-168. Brno: Masaryk University Press.

Boulton, Alex, and Pascual Pérez-Paredes. 2014.

"Editorial: Researching New Uses of Corpora for Language Teaching and Learning."

$\operatorname{ReCALL}, 26$, no. 2: 121-127.
Bower, Jack, and Satomi Kawaguchi. 2011. "Negotiation of Meaning and Corrective Feedback in Japanese/English eTandem." Language Learning \& Technology, 15, no. 1: 41-71.

Bowles, Melissa. 2005. Effects of Verbalization Condition and Type of Feedback on L2 Development in a CALL Task. PhD dissertation, Georgetown University.

Brandl, Klaus. 1995. "Strong and Weak Students' Preferences for Error Feedback Options and Responses." Modern Language Journal, 79, no. 2: 194-211.

Burston, Jack. 1989. “Towards Better Tutorial CALL: A Matter of Intelligent Control." CALICO Journal, 6, no. 4: 75-89.

Burston, Jack. 2001. "Exploiting the Potential of a Computer-Based Grammar Checker in Conjunction with Self-Monitoring Strategies with Advanced Level Students of French." CALICO Journal, 18, no. 3: 499-515.

Chambers, Angela. 2005. "Integrating Corpus Consultation in Language Studies." Language Learning \& Technology, 9, no. 2: 111-125.

Chapelle, Carol. 1998. "Multimedia CALL: Lessons to be Learned from Research on Instructed SLA." Language Learning $\mathcal{E}$ Technology, 2, no. 1: 21-39.

Chun, Dorothy. 1994. “Using Computer Networking to Facilitate the Acquisition of Interactive Competence." System, 22, no. 1: 17-31.

Cobb, Thomas, and Alex Boulton. 2015. "Classroom Applications of Corpus Analysis." In The Cambridge Handbook of English Corpus Linguistics, edited by Douglas Biber and Randy Reppen, 478-497. Cambridge: Cambridge University Press.

Conrad, Susan. 2000. “Will Corpus Linguistics Revolutionize Grammar Teaching in the 21st Century?" TESOL Quarterly, 34, no. 3: 548-559. 
Cotos, Elena. 2014. "Enhancing Writing Pedagogy with Learner Corpus Data." $\operatorname{ReCALL}, 26$, no. 2: 202-224.

Cowan, Ron, Jinhee Choo, and Gabseon Sunny Lee. 2014. "ICALL for Improving Korean L2 Writers' Ability to Edit Grammatical Errors." Language Learning \& Technology, 18, no. 3: 193-207.

Darhower, Mark. 2014. “Synchronous ComputerMediated Dynamic Assessment: A Case Study of L2 Spanish Past Narration." CALICO Journal, 31, no. 2: 221-243.

Davies, Mark. 2008. The Corpus of Contemporary American English: 450 Million Words, 1990Present. Accessed February 15, 2016. http:// corpus.byu.edu/coca/

Dickinson, Markus, Soojeong Eom, Yunkyoung Kang, Chong Min Lee, and Rebecca Sachs. 2008. "A Balancing Act: How Can Intelligent Computer-generated Feedback Be Provided in Learner-to-Learner Interactions?"

Computer Assisted Language Learning, 21, no. 4: 369-382.

Ellis, Rod. 1993. "The Structural Syllabus and Second Language Acquisition." TESOL Quarterly, 27, no. 1: 91-113.

Ellis, Rod, Helen Basturkmen, and Shawn Loewen. 2001. "Preemptive Focus on Form in the ESL Classroom." TESOL Quarterly, 35, no. 3: $407-432$.

Elola, Idoia, and Ana Oskoz. 2010. "Collaborative Writing: Fostering Foreign Language and Writing Conventions Development." Language Learning \& Technology, 14, no. 3: 30-49.

Elola, Idoia, and Ana Oskoz. 2011. "Writing Between the Lines: Acquiring the Presentational Mode through Social Tools." In Present and Future Promises of CALL: From Theory and Research to New Directions in Language Teaching, edited by Nike Arnold and Lara Ducate, 171-210. San Marcos, TX: CALICO.

Estling Vannestål, Maria, and Hans Lindquist. 2007. "Learning English Grammar with a Corpus: Experimenting with Concordancing in a University Grammar Course." ReCALL, 19, no. 3: 329-350.

Frankenberg-García, Ana. 2014. "The Use of Corpus Examples for Language Comprehension and Production." ReCALL, 26, no. 2: 128-146.

Gamon, Michael, Claudia Leacock, Chris Brockett, William Dolan, Jianfeng Gao, Dmitriy Belenko, and Alexandre Klementiev. 2009. "Using Statistical Techniques and Web Search to Correct ESL Errors." CALICO Journal, 26, no. 3: 491-511.
Gaskell, Delian, and Thomas Cobb. 2004. "Can Learners Use Concordance Feedback for Writing Errors?" System, 32, no. 3: 301-319.

Gass, Susan. 1997. Input, Interaction and the Second Language Learner. Mahwah, NJ: Lawrence Erlbaum.

Granger, Sylviane. 2003. "Error-tagged Learner Corpora and CALL: A Promising Synergy." CALICO Journal, 20, no. 3: 465-480.

Hamel, Marie-Josée. 2010. "Prototype d'un Dictionnaire Électronique de Reformulation pour Apprenants Avancés de Français Langue Seconde." Cahiers de l'APLIUT XXIX, 1: 73-82.

Hegelheimer, Volker. 2006. "Helping ESL Writers through a Multimodal, Corpus-based, Online Grammar Resource." CALICO Journal, 24, no. 1:5-31.

Hegelheimer, Volker, and Carol Chapelle. 2000. "Methodological Issues in Research on Learner-Computer Interactions in CALL." Language Learning \& Technology, 4, no. 1: 41-59.

Heift, Trude. 2002. "Learner Control and Error Correction in ICALL: Browsers, Peekers and Adamants." CALICO Journal, 19, no. 3 : 295-313.

Heift, Trude. 2004. "Corrective Feedback and Learner Uptake in CALL." ReCALL, 16, no. 2: 416-431.

Heift, Trude. 2010. "Developing an Intelligent Tutor." CALICO Journal, 27, no. 3: 443-459. Heift, Trude. 2013. "Preemptive Feedback in CALL." In Interaction in Diverse Educational Settings, edited by Alison Mackey and Kim McDonough, 189-207. Philadelphia: John Benjamins.

Heift, Trude, and Anne Rimrott. 2008. "Learner Responses to Corrective Feedback for Spelling Errors in CALL." System, 36, no. 2: 196-213.

Higgins, John, and Tim Johns. 1984. Computers in Language Learning. London: Collins.

Hirotani, Maki. 2009. "Synchronous versus Asynchronous CMC and Transfer to Japanese Oral Performance." CALICO Journal, 26, no. 2: 413-438.

Hubbard, Phil, and Claire B. Siskin. 2004. "Another Look at Tutorial CALL." ReCALL,16, no. 2: 448-461.

Johns, Tim. 1986. "Micro-Concord: a Language Learner's Research Tool." System, 14, no. 2: 151-162.

Johns, Tim. 1991. "Should You Be Persuaded: Two Examples of Data-driven Learning Materials." English Language Research Journal, 4: 1-16. 
Kennedy, Claire, and Tiziana Miceli. 2010.

"Corpus-Assisted Creative Writing:

Introducing Intermediate Italian Learners to a

Corpus as a Reference Resource." Language

Learning \& Technology, 14, no. 1: 28-44.

Kern, Richard G. 1995. "Restructuring Classroom

Interaction with Networked Computers:

Effects on Quantity and Characteristics of

Language Production." The Modern Language

Journal, 79, no. 4: 457-476.

Krashen, Stephen. 1988. Second Language

Acquisition and Second Language Learning.

Englewood Cliffs, NJ: Prentice-Hall

International.

Kregar, Sandra. 2011. Relative Effectiveness of

Corrective Feedback Types in Computer-

Assisted Language Learning. $\mathrm{PhD}$ dissertation, Florida State University.

Lado, Beatriz, Harriet Wood Bowden, Catherine Stafford, and Cristina Sanz. 2014.

"A Fine-grained Analysis of the Effects of

Negative Evidence with and without

Metalinguistic Information in Language

Development." Language Teaching Research,

18, no. 3: 320-244.

Lantolf, Jim, and Steven Thorne. 2006.

Sociocultural Theory and the Genesis of $L 2$

Development. Oxford: Oxford University Press.

Levy, Michael.1997. Computer-Assisted Language

Learning: Context and Conceptualisation. Oxford: Oxford University Press.

Liou, Hsien-Chin, Samuel Wang, and Yuli Hung-Yeh. 1992. "Can Grammatical CALL Help EFL Writing Instruction?" CALICO Journal, 10, no. 1: 23-44.

Little, David. 1991. Learner Autonomy 1: Definitions, Issues, and Problems. Dublin: Authentik.

Loewen, Shawn, and Rosemary Erlam. 2006. "Corrective Feedback in the Chatroom: An Experimental Study." Computer Assisted Language Learning, 19, no. 1: 1-14.

Long, Michael. 1996. "The Role of the Linguistic Environment in Second Language

Acquisition." In Handbook of Second Language Acquisition, edited by William Ritchie and Tey K. Bhatia, 413-468. San Diego, CA: Academic Press.

Lyster, Roy. 2007. Learning and Teaching Languages through Content: A Counterbalanced Approach. Amsterdam: John Benjamins.

Metcalfe, Peter. 1992. "CALL, the ForeignLanguage Undergraduate and the Teaching of Grammar: A Linguistic and Political

Battlefield." ReCALL, 4, no. 7: 3-5.
Meurers, Detmar, Ramon Ziai, Luiz Amaral, Adriane Boyd, Aleksandar Dimitrov, Vanessa Metcalf, and Niels Ott. 2010. "Enhancing Authentic Web Pages for Language Learners." In Proceedings of the NAACL HLT 2010 Fifth Workshop on Innovative Use of NLP for Building Educational Applications, 10-18. Association for Computational Linguistics, 2010.

Moreno, Nina. 2007. The Effects of Type of Task and Type of Feedback on L2 Development in CALL. PhD dissertation, Georgetown University.

Murphy, Philip. 2007. "Reading Comprehension Exercises Online: The Effects of Feedback, Proficiency and Interaction." Language Learning E Technology, 11, no. 3: 107-129.

Nagata, Noriko. 1993. "Intelligent Computer Feedback for Second Language Instruction." Modern Language Journal, 77, no. 3: 330-338.

Nagata, Noriko. 1996. "Computer vs. Workbook Instruction in Second Language Acquisition." CALICO Journal, 14, no. 1: 53-75.

Nagata, Noriko. 2009. "Robo-Sensei's NLP-Based Error Detection and Feedback Generation." CALICO Journal, 26, no. 3: 562-579.

Oskoz, Ana. 2009. “Learners' Feedback in Online Chats: What Does it Reveal about Students' Learning." CALICO Journal, 27, no. 1: 48-68.

Petersen, Ken. 2010. Implicit Corrective Feedback in Computer-Guided Interaction. Does Mode Matter? PhD dissertation, Georgetown University.

Pujolà, Joan-Tomàs. 2002. “CALLing for Help: Researching Language Learning Strategies Using Help Facilities in a Web-Based Multimedia Program." ReCALL, 14, no. 2: 253-262.

Pusack, Jim. 1983. "Answer-Processing and Error Correction in Foreign Language CAI." System, 11, no. 1: 53-64.

Reppen, Randy. 2010. Using Corpora in the Language Classroom. Cambridge: Cambridge University Press.

Robinson, Peter, and Nick C. Ellis, eds. 2008. Handbook of Cognitive Linguistics and Second Language Acquisition. London: Routledge.

Römer, Ute. 2011. "Corpus Research Applications in Second Language Teaching." Annual Review of Applied Linguistics, 31, no. 1: 205-225.

Rosa, Elena, and Ronald Leow. 2004.

"Computerized Task-Based Exposure, Explicitness and Type of Feedback on Spanish L2 Development." Modern Language Journal, 88, no. 2: 192-217. 
Salaberry, M. Rafael 2000. “L2 Morphosyntactic Development in Text-based Computermediated Communication." Computer Assisted Language Learning, 13, no. 1: 5-27.

Samburskiy, Denis, and Joy Quah. 2014. "Corrective Feedback in Asynchronous Online Interaction: Developing Novice Online Language Instructors." CALICO Journal, 31, no. 2: 158-178.

Sanz, Cristina, and Kara Morgan-Short. 2004.

"Positive Evidence Versus Explicit Rule Presentation and Explicit Negative Feedback: A Computer-Assisted Study." Language Learning, 54, no. 1: 35-78.

Sauro, Shannon. 2009. "Computer-mediated Corrective Feedback and the Development of L2 Grammar." Language Learning \& Technology, 13, no. 1: 96-120.

Schmidt, Richard. 1990. "The Role of Consciousness in Second Language Learning." Applied Linguistics, 11, no. 2: 129-158.

Schulze, Mathias, and Trude Heift. 2013. "Intelligent CALL." In Contemporary ComputerAssisted Language Learning, edited by Michael Thomas, Hayo Reinders, and Mark Warschauer, 249-265. London and New York: Continuum.

Sharwood Smith, Michael. 1993. "Input

Enhancement in Instructed SLA." Studies in Second Language Acquisition, 15, no. 2: 165-179.

Shekary, Moozeh, and Mohammad Hassan Tahririan. 2006. "Negotiation of meaning and noticing in text-based online chat." Modern Language Journal, 90, no. 4: 557-573.

Simpson, Rita C., Sarah L. Briggs, Janine Ovens, and John M. Swales. 2002. The Michigan Corpus of Academic Spoken English. Ann Arbor, MI: The Regents of the University of Michigan.

Accessed February 15, 2016. http://quod.lib. umich.edu/cgi/c/corpus/corpus?page=home ; $=$ micase $; c c=$ micase

Smart, Jonathan. 2014. “The Role of Guided Induction in Paper-based Data-driven Learning." ReCALL, 26, no. 2: 184-201. Smith, Bryan. 2009. "The Relationship between Scrolling, Negotiation, and Self-initiated Self- repair in a SCMC Environment." CALICO Journal, 26, no. 2: 231-345.

Smith, Bryan. 2012. "Eye Tracking as a Measure of Noticing: A Study of Explicit Recasts in SCMC." Language Learning \& Technology, 16, no. 3: 53-81.

Sotillo, Susana. 2005. “Corrective Feedback via Instant Messenger Learning Activities in
NS-NNS and NNS-NNS Dyads." CALICO Journal, 22, no. 3: 467-496.

Stockwell, Glenn, and Michael Harrington. 2003. "The Incidental Development of L2 Proficiency in NS-NNS Email Interactions." CALICO Journal, 20, no. 2: 337-359.

Swain, Merrill, and Sharon Lapkin. 1998. "Interaction and Second Language Learning: Two Adolescent French Immersion Students Working Together." Modern Language Journal, 82, no. 3: 320-338.

ten Hacken, Pius, and Cornelia Tschichold. 2001. "Word Manager and CALL: Structured Access to the Lexicon as a Tool for Enriching Learners' Vocabulary." ReCALL 13, no. 1: 121-131.

Thorne, Steven L. 2003. "Artifacts and Culturesof-Use in Intercultural Communication." Language Learning and Technology, 7, no. 2: 38-67.

Tian, Shiauping. 2005. “The Impact of Learning Tasks and Learner Proficiency on the Effectiveness of Data-driven Learning." Journal of Pan-Pacific Association of Applied Linguistics, 9, no. 2: 263-275.

Tono, Yukio, Yoshiho Satake, and Aika Miura. 2014. "The Effects of Using Corpora on Revision Tasks in L2 Writing with Coded Error Feedback." ReCALL, 26, no. 2: 147-162.

Vinagre, Margarita, and Beatriz Muñoz. 2011. "Computer-Mediated Corrective Feedback and Language Accuracy in Telecollaborative Exchanges." Language Learning \& Technology, 15, no. 1: 72-103.

Vinther, Jane. 2005. "Cognitive Processes at Work in CALL." Computer Assisted Language Learning, 18, no. 4: 251-271.

Vyatkina, Nina. 2013. "Discovery Learning and Teaching with Electronic Corpora in an Advanced German Grammar Course." Die Unterrichtspraxis/Teaching German, 46, no. 1: 44-61.

Vyatkina, Nina. 2016a. "Data-driven Learning for Beginners: The Case of German VerbPreposition Collocations." ReCALL, 28, no. 2: 207-226.

Vyatkina, Nina. 2016b. "Data-driven Learning of Collocations: Learner Performance, Proficiency, and Perceptions." Language Learning \& Technology, 20, no. 3: 159-179.

Ware, Paige, and Robert O'Dowd. 2008. "Peer

Feedback on Language Form in Telecollaboration." Language Learning $\mathcal{E}$ Technology, 12, no. 1: 43-63.

Warschauer, Mark. 2002. “A Developmental

Perspective on Technology in Language 
Education." TESOL Quarterly, 36, no. 3: 453-475.

Weischedel, Ralph, Wilfried Voge, and Mark James. 1978. "An Artificial Intelligence Approach to Language Instruction." Artificial Intelligence, 10, no. 3: 225-240.

Williams, Anthony, Graham Davies, and Inrid Williams. 1981. Apfeldeutsch. London: Wida Software.

Wood, Peter. 2011. "Computer Assisted Reading in German as a Foreign Language. Developing and Testing an NLP-Based Application." CALICO Journal, 28, no. 3: 662-676.
Yilmaz, Yusel. 2012. "The Relative Effects of Explicit Correction and Recasts on Two Target Structures via Two Communication Modes." Language Learning, 62, no. 4: 1134-1169. Zeng, Gang, and Shigenobu Takatsuka. 2009. "Text-based Peer-peer Collaborative Dialogue in a Computer-mediated Learning Environment in the EFL Context." System, 37, no. 3: 434-446.

Ziegler, Nicole. 2013. Synchronous ComputerMediated Communication and Interaction: A Research Synthesis and Meta-Analysis. PhD dissertation, Georgetown University. 